\title{
Management of Phylloid Sarcomas: A Retrospective Study of 12 Cases
}

\author{
Kanta Ka1,2* Abdoul Halim Bague ${ }^{3}$, Ibrahim Mounkeila4, Mamadou Lassana Foba ${ }^{5}$, \\ N. Zongo ${ }^{3}$, Davide Soldato², Filippo Dall'Olio², Mamadou Moustapha Dieng6, \\ Papa Macoumba Gaye ${ }^{1,6}$, Daniele Presti ${ }^{2,7}$
}

\author{
${ }^{1}$ Radiotherapy Department, Centre Hospitalier National Universitaire Dalal Jamm de Guédiawaye, Guédiawaye, Senegal \\ ${ }^{2}$ School of Cancer Sciences, Paris Sud, Orsay, French \\ ${ }^{3}$ Unité D’oncologie Chirurgicale, CHU Yalgado Ouedraogo, Ouagadougou, Burkina Faso \\ ${ }^{4}$ Servie d'Oncologie Institut Joliot Curie, Centre Hospitalier Universitaire Aristide Le Dantec, Dakar, Senegal \\ ${ }^{5}$ Department of Plastic Surgery, Aristide Le Dantec University Hospital, Dakar, Senegal \\ ${ }^{6}$ University Cheikh Anta Diop of Dakar, Dakar, Senegal \\ ${ }^{7}$ Medical Oncology Service, ICS Maugeri IRCCS SpA, University of Pavia, Pavia, Italy \\ Email: *ka.kanta04@gmail.com, halimbagq@yahoo.fr, msibrahim83@yahoo.fr, mamadlass1986@gmail.com, \\ daniele.presti91@gmail.com, davide.soldato@gustaveroussy.fr, Filippo.dall'olio@gustaveroussy.fr
}

How to cite this paper: Ka, K., Bague, A.H., Mounkeila, I., Foba, M.L., Zongo, N., Soldato, D., Dall'Olio, F., Dieng, M.M., Gaye, P.M. and Presti, D. (2021) Management of Phylloid Sarcomas: A Retrospective Study of 12 Cases. Advances in Breast Cancer Research, 10, 25-33.

https://doi.org/10.4236/abcr.2021.102002

Received: February 21, 2021

Accepted: April 12, 2021

Published: April 15, 2021

Copyright $\odot 2021$ by author(s) and Scientific Research Publishing Inc. This work is licensed under the Creative Commons Attribution-NonCommercial International License (CC BY-NC 4.0). http://creativecommons.org/licenses/by-nc/4.0/ (c) (i) () Open Access

\begin{abstract}
Background: Phylloid sarcomas are rare. There is not enough data to codify the management. Objectives: The objective was to study the clinical and therapeutic aspects and the fate of patients after a follow-up of at least 4 years. Thus contributing to the limited body of knowledge on these tumors. Methods: a retrospective analysis of the files from 2013 to 2017 was carried out and patients were followed up until 2021at Hassan II Hospital. Epidemiological, clinical and therapeutic aspects were studied. Survival was calculated using the Kaplan-Meier method. Results: We collected 12 charts of patients treated for phyllodeal sarcoma from 2013 to 2017. The median age was 43 years. The circumstance of discovery was marked by the presence of nodule in all patients. The coupled echo-mammography examination classified the nodules, ACR 4 in 7 patients and ACR 3 in 3 and ACR 5 in 2 patients. Histological examination revealed a phylloid sarcoma in 11 patients and a borderline phylloid tumor in 1 patient. All patients had radical surgery with positive margins in 2 patients, $16.66 \%$. One patient had revision surgery. Histological examination of the surgical specimens showed phylloid sarcoma on all specimens. All patients had adjuvant radiotherapy with doses of $50 \mathrm{~Gy}$ in 25 fractions of $2 \mathrm{~Gy}$ and a boost of $10 \mathrm{~Gy}$ was done in one patient. The median spread of radiotherapy was 37 days. Grade 1 and 2 skin toxicities were noted in 5 and 3 patients respectively. The median time from surgery to radiotherapy was 2.95 months. 3 patients relapsed after 13.6 months of follow-up. The
\end{abstract}


recurrence-free survival at 1 and 3 years was $83 \%$ and $75 \%$ respectively. Overall survival at 3 and 5 years was $83 \%$ and $75 \%$ respectively. Conclusion: This is a rare entity which requires randomized trials to codify its management. It would seem that the multidisciplinary approach, associating surgery \pm radiotherapy, is a good option.

\section{Keywords}

Phylloid Sarcoma, Radiotherapy, Survival

\section{Introduction}

The World Health Organization classifies phylloid tumors as benign, borderline, or malignant, taking into account tumor margins, stromal growth, mitotic index, cell atypical and necrosis [1]. Breast sarcomas are rare and account for less than $1 \%$ of cancers (less than $5 \%$ of localized sarcomas) [2]. Phylloid sarcomas account for between $0.3 \%$ and $1 \%$ of breast tumors [3]. Diagnosis is often made in women in their fifties during a consultation following a self-test of a breast mass [4] [5] [6]. There is no predominance for one breast in particular [7] [8].

Surgery is the standard treatment for phylloid sarcomas, particularly the radical type, which is considered to be the gold standard for breast sarcoma surgery [4] [8] [9] [10].

The value of adjuvant radiotherapy is controversial. While some authors have shown that it is effective in ensuring the disease survives without relapse, others are not convinced of the need for this treatment [11] [12].

The role of chemotherapy remains uncertain [13]. Morales-Vazquez et al. have shown that adjuvant chemotherapy has no effect on survival [14].

At present, treatment is usually a combination of surgery, radiotherapy and sometimes chemotherapy [13]. Local and distant relapse rates are $20 \%-30 \%$ [15] [16].

There is very little data on the knowledge of phylloid sarcomas to enable a solid therapeutic consensus to be reached.

The aim of this work was to study the clinical, therapeutic and prognostic aspects of phylloid sarcomas of the breast.

\section{Materials and Methods}

A retrospective analysis of records from 2013 to 2017 was carried out and a follow-up of patients was carried out until 2021. 12 patient files were selected.

\subsection{Patients}

All patients treated in radiotherapy for phylloid sarcoma on the basis of histology at diagnosis.

The tumor size was chosen on the basis of an anatomopathological study of 
the surgical specimen.

A descriptive analysis of the clinical, therapeutic and prognostic aspects is made.

Patients whose treatment was carried out in other centers and who had come for follow-up in our hospital were excluded, as well as those whose histological diagnosis was not formal.

\subsection{Treatment}

A radical first surgery was performed in all patients with the possibility of revision depending on the state of the resection margins.

Adjuvant radiotherapy was performed in all patients with total doses of 50 to 60 Gy and 2 Gy per fraction.

Chemotherapy was only carried out at the time of recurrence as proven by clinical, radiological and histological examinations.

\subsection{Statistical Analysis}

The continuous variables were summarised as: mean, median, standard deviation.

Categorical variables were noted in $\mathrm{n}$ and (\%).

Overall survival and recidivism-free survival were calculated and the curves made by the Kaplan-Meier method.

Relapse-free survival corresponds to the date of the end of radiotherapy until the clinical and/or radiological diagnosis of relapse of the disease.

Overall survival was calculated from the date of consultation in gynaecological oncology to the date of last news.

\section{Results}

We collected 12 charts of patients treated for phyllodeal sarcoma from 2013 to 2017. The characteristics of the patients are summarised in Table 1.

The median age was 43 years $(\min 23, \max 65) .5$ patients were in menopause. 3 patients had a surgical history of lumpectomy for grade I phylloid tumor. The circumstance of discovery was marked by the presence of nodule in all patients. The coupled echo-mammography examination classified the nodules, ACR 4 in 7 patients and ACR 3 in 3 and ACR 5 in 1 patient. The TNM AJCC 8th edition classification of these patients showed: $42 \%(5 / 12)$ T4N0M0, $8 \%(1 / 12)$ T4N1M0, 8\% (1/12) T3N1M0, 17\% (2/12) T3N0M0, 8\% (1/12) T2N1M0 and $17 \%(2 / 12)$ T1N0M0. Histological examination revealed a phylloid sarcoma in 11 patients and a borderline phylloid tumor in 1 patient. All patients had radical surgery with positive margins in 2 patients, i.e. $16.66 \%$. One patient had revision surgery. Histological examination of the surgical specimens showed phyllode sarcoma on all specimens. All patients had adjuvant radiotherapy with doses of $50 \mathrm{~Gy}$ in 25 fractions of $2 \mathrm{~Gy}$ and a boost of $10 \mathrm{~Gy}$ was done in one patient. The median spread of radiotherapy was 37 days $(\min 32$, $\max 64)$. Grade 1 and 2 skin toxicities were noted in 5 and 3 patients respectively. The median time from 
Table 1. Socio-demographic and clinical characteristics of the patients.

\begin{tabular}{|c|c|}
\hline Characteristics & Number/Percent \\
\hline \multicolumn{2}{|l|}{ Menopause } \\
\hline yes & $5(41.66)$ \\
\hline No & $7(58.34)$ \\
\hline \multicolumn{2}{|l|}{ Number of Pregnancies } \\
\hline nulliparous & $6(50)$ \\
\hline pauciparious & $3(25)$ \\
\hline multiparious & $3(25)$ \\
\hline \multicolumn{2}{|l|}{ Contraception } \\
\hline yes & $1(8.34)$ \\
\hline No & $11(91.66)$ \\
\hline \multicolumn{2}{|l|}{ Medical History } \\
\hline yes (Hepatite B\&C) & $1(8.34)$ \\
\hline No & $11(91.66)$ \\
\hline \multicolumn{2}{|l|}{ Surgical History } \\
\hline yes & $3(25)$ \\
\hline No & $9(75)$ \\
\hline \multicolumn{2}{|l|}{ Family History of Cancer } \\
\hline yes & $1(8.34)$ \\
\hline No & $11(91.66)$ \\
\hline \multicolumn{2}{|l|}{ Site } \\
\hline right & $6(50)$ \\
\hline left & $6(50)$ \\
\hline \multicolumn{2}{|l|}{ Nodule } \\
\hline yes & $12(100)$ \\
\hline No & 0 \\
\hline \multicolumn{2}{|l|}{ TNM } \\
\hline T1N0M0 & $2(17)$ \\
\hline T2N1M0 & $1(8)$ \\
\hline T3N0M0 & $2(17)$ \\
\hline T3N1M0 & $1(8)$ \\
\hline T4N0M0 & $5(42)$ \\
\hline T4N1M0 & $1(8)$ \\
\hline \multicolumn{2}{|l|}{ Margin Statements } \\
\hline negative & $10(83.33)$ \\
\hline positive & $2(16.67)$ \\
\hline \multicolumn{2}{|l|}{ Total Dose } \\
\hline 50 & $11(91.66)$ \\
\hline 60 & $1(8.34)$ \\
\hline \multicolumn{2}{|l|}{ Etalement (Days) } \\
\hline Mediane & $37(\min 32, \max 64)$ \\
\hline average & 40.8 \\
\hline standard deviation & 9.4 \\
\hline \multicolumn{2}{|l|}{ Complications } \\
\hline No & $4(33.33)$ \\
\hline Radiodermite grade 1 & $5(41.66)$ \\
\hline Radiodermite grade 2 & $3(25.01)$ \\
\hline \multicolumn{2}{|l|}{ Recurrence } \\
\hline yes & $3(25)$ \\
\hline No & $9(75)$ \\
\hline \multicolumn{2}{|l|}{ Recidivism Period (Months) } \\
\hline Average & $13.6(\min 5.5, \max 28.2)$ \\
\hline Standard deviation & 12.6 \\
\hline
\end{tabular}


surgery to radiotherapy was 2.95 months (min 0.43, $\max 8.85$ ). 3 patients relapsed after 13.6 months of follow-up ( $\min 5.5, \max 28.2)$. The recurrence-free survival at 1 and 3 years was $83 \%$ and $75 \%$ respectively (Figure 1). Overall survival at 3 and 5 years was $83 \%$ and $75 \%$ respectively (Figure 2).

\section{Kaplan-Meier Graphe de Survie sans récidive}

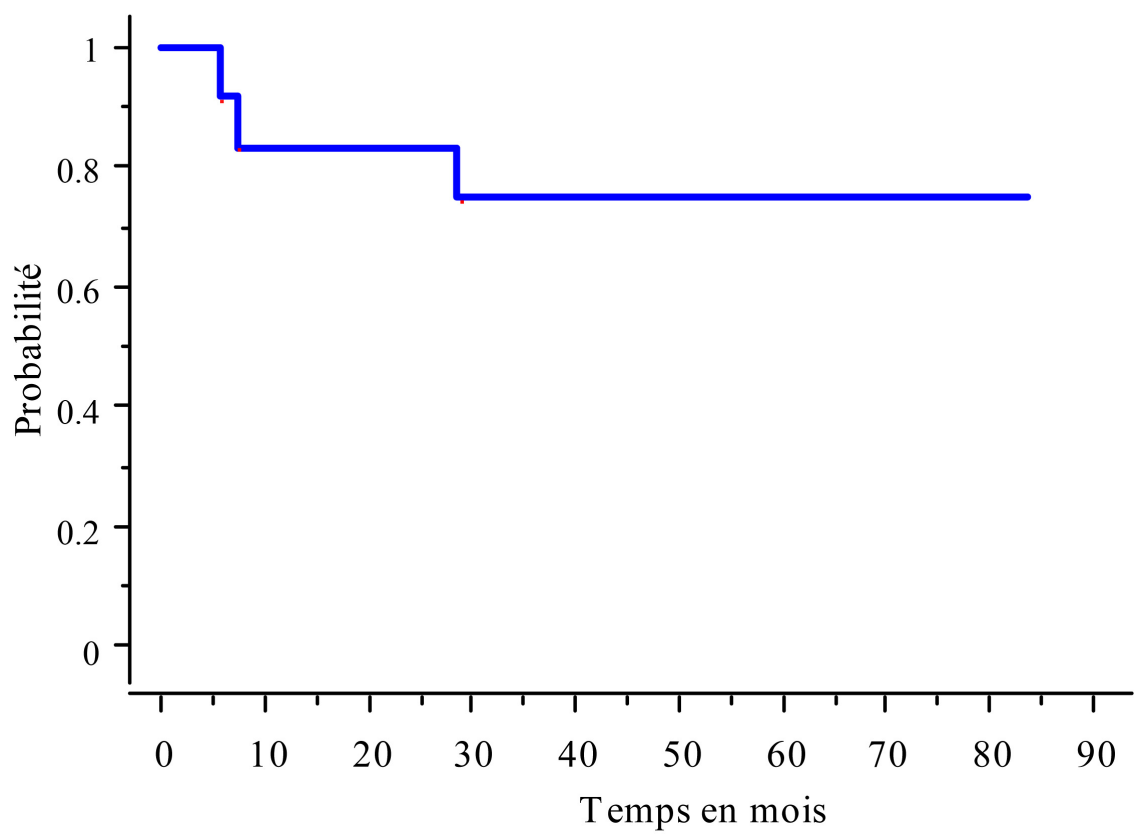

Figure 1. Survival curve without recurrence post-radiotherapy. Survival without recidivism at 1 year $=83 \%$; Survival at 5 years $=$ Survival at 3 years $=75 \%$.

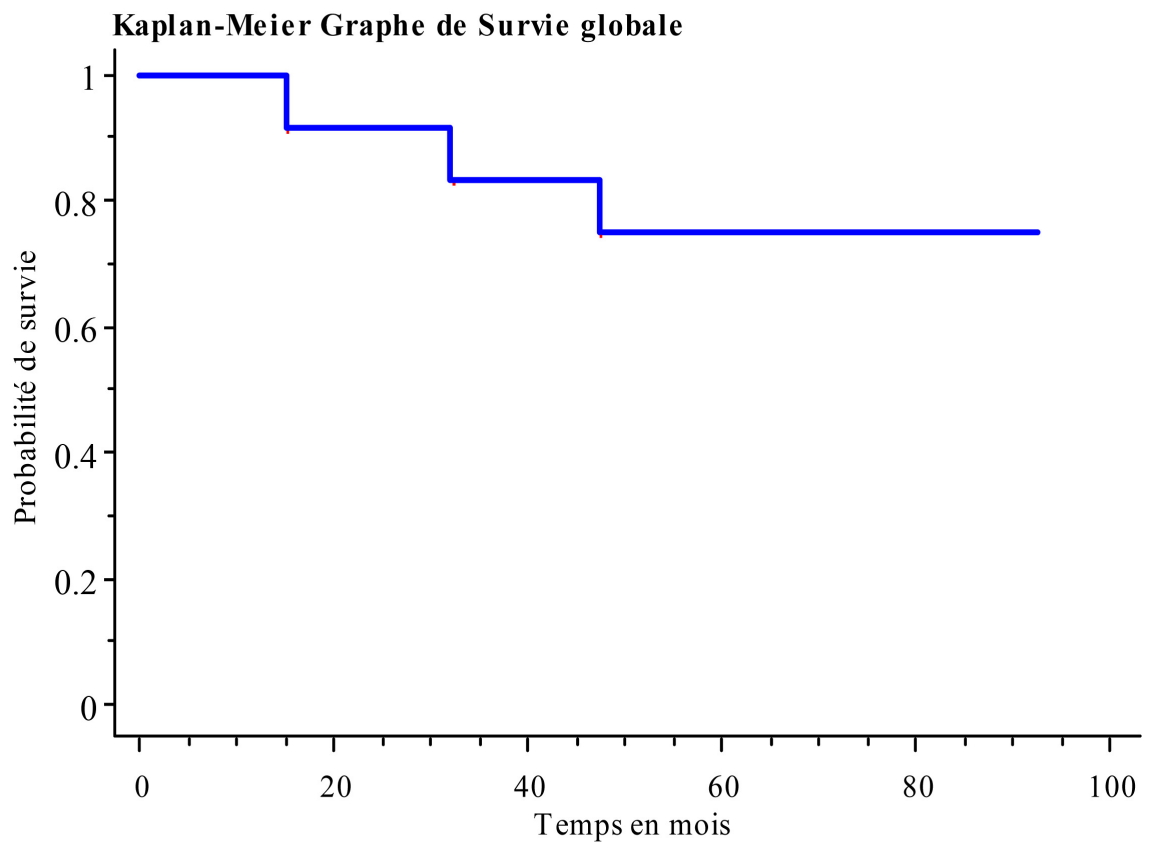

Figure 2. Overall survival curve. Overall survival at 1 year $=100 \%$; Survival at 3 years $=$ $83 \%$ Overall survival at 5 years $=75 \%$. 


\section{Discussion}

Like most breast cancers, the predominance is female with a variation of 0 to $12 \%$ in the literature [17] [18]. The diagnosis is usually made around $50-60$ years of life [4] [5]. In our series, there were no men and the median age was 43 years $(\min 23, \max 65)$. The clinical presentation is often a breast mass with or without pain [6]. The main reason for consultation in our series was the occurrence of a mammary nodule at the time of self-testing. There is equivalence in the literature series of the damage to both breasts [7] [8].

Tumor size is often large, related to neglect and the rapid development of phylloid sarcomas. It ranges from 4.8 to $12.5 \mathrm{~cm}$, and can even reach $41 \mathrm{~cm} \mathrm{[4]}$ [5]. In our series the median tumor size was $16.5 \mathrm{~cm}(\min 3.5, \max 30)$. Tumor size is an important prognostic factor. In the series of Fields et al. it is associated with an overall survival of $83 \%$ for sizes less than $5 \mathrm{~cm}$ compared to $43 \%$ for sizes greater than $5 \mathrm{~cm}(\mathrm{p}=0.041)$ [19].

Surgery is the standard treatment for phylloid sarcomas [4] [10].

Simple mastectomy is considered the gold standard for breast sarcomas [8] [9]. In our series all patients had a mastectomy, 5 of them with negative associated lymph node removal. This radical strategy is based on the study by Berg et al. which shows high rates of local recurrence with conservative treatment than with mastectomy [20]. Nevertheless, the specific survival probability was comparable between conservative and radical treatment. The question did not arise in our study since the tumor sizes did not allow conservative treatment. Since the principle of treatment for soft sarcomas is to add radiotherapy to surgery, Zelek et al. recommended that the same should be done for phylloid sarcomas of the breast [17]. Thus the study by Belkacemi et al. seems to prove them right with a local control rate at 10 years of $86 \%$ with adjuvant radiotherapy compared to $59 \%$ without radiotherapy $(p=0.02)$ [11]. However, the probability of overall survival did not change. Some authors did not see the benefit of adjuvant radiotherapy in terms of recurrence-free survival and overall survival. The series of Confavreux et al., is a perfect illustration of this. It showed a local recurrence rate at 3 years of $52.4 \%$ without radiotherapy compared to $47.8 \%$ after adjuvant radiotherapy $(\mathrm{p}=0.6)[12]$.

In our series, all the patients underwent adjuvant radiotherapy with grade 1 skin toxicity in 5 cases and grade 2 in 3 cases. The recurrence-free survival rates at 1 and 3 years were $83 \%$ and $75 \%$ respectively. The overall survival rates did not change much, $83 \%$ at 3 years, $75 \%$ at 5 years. This series showed that adjuvant radiotherapy is not associated with a significant decrease in local recurrence.

Since there is very little data on breast sarcomas, indications for radiotherapy use should follow those for soft tissue sarcomas [10]. Therefore, as noted in the literature, any tumor with these characteristics can benefit from radiotherapy [17] [21] [22]:

- High histological grade; 
- Diameter of more than $5 \mathrm{~cm}$;

- Healthy surgical margins of less than $1 \mathrm{~cm}$;

- A conservative treatment.

The role of chemotherapy in the management of phylloid sarcomas has not been established [13]. The study by Morales-Vazquez et al. showed no effect on survival of adjuvant chemotherapy using doxorubicin and dacarbazine. They included 28 patients treated by primary surgery for phyllodeal sarcoma. 17 patients had adjuvant chemotherapy, 25\% had adjuvant radiotherapy. The 5-year recurrence-free survival rate was $58 \%$ for patients who received adjuvant treatment and $86 \%$ for patients who did not (p 1/4 0.17); and the median survival after relapse was 6.5 months [14].

None of our patients had chemotherapy associated with local treatment when the disease was localized. Of the 3 patients who relapsed, only one had local and metastatic relapse chemotherapy with doxorubicin and xgeva. They all died.

Compared to other sarcomas (angiosarcomas), phylloid sarcomas have a better prognosis [17].

The Belkacémi et al. series showed that the only independent prognostic factor for local control was adjuvant radiotherapy [11].

As our study is retrospective with few patients, it is difficult to be formal about the role of adjuvant radiotherapy. However the results seem to be in line with the Belkacemi study [11].

\section{Conclusion}

This work adds to the knowledge of rare phylloid sarcomas. The value of adjuvant radiotherapy appears to be demonstrated. However, it would be useful to conduct randomized trials to standardize this practice.

\section{Conflicts of Interest}

The authors declare no conflicts of interest regarding the publication of this paper.

\section{References}

[1] Lakhani, S.R., International Agency for Research on Cancer Press and World Health Organization (2012) WHO Classification of Tumours of the Breast. International Agency for Research on Cancer Press, Lyon.

[2] Lim, S.Z., Ong, K.W., Tan, B.K., Selvarajan, S. and Tan, P.H. (2016) Sarcoma of the Breast: An Update on a Rare Entity. Journal of Clinical Pathology, 69, 373-381. https://doi.org/10.1136/jclinpath-2015-203545

[3] Tavassoli, F.A. and Devilee, P. (2003) Pathology and Genetics of Tumors of the Breast and Female Genital Organs. World Health Organization Classification of Tumors, Vol. 4, International Agency for Research on Cancer Press, Lyon.

[4] Al-Benna, S., Poggemann, K., Steinau, H.U. and Steinstraesser, L. (2010) Diagnosis and Management of Primary Breast Sarcoma. Breast Cancer Research and Treatment, 122, 619-626. https://doi.org/10.1007/s10549-010-0915-y

[5] Lahat, G., Lev, D., Gerstenhaber, F., Madewell, J., Le-Petross, H. and Pollock, R.E. 
(2012) Sarcomas of the Breast. Expert Review of Anticancer Therapy, 12, 1045-1051. https://doi.org/10.1586/era.12.82

[6] Trent 2nd, I.J., Benjamin, R.S. and Valero, V. (2001) Primary Soft Tissue Sarcoma of the Breast. Current Treatment Options in Oncology, 2, 169-176.

https://doi.org/10.1007/s11864-001-0059-8

[7] Norris, H.J. and Taylor, H.B. (1968) Sarcomas and Related Mesenchymal Tumors of the Breast. Cancer, 22, 22-28.

https://doi.org/10.1002/1097-0142(196807)22:1\%3C22::AID-CNCR2820220105\%3E 3.0.CO;2-R

[8] Gabriele, R., Borghese, M., Corigliano, N., Barbaro, M. and Conte, M. (2000) Phyllodes Tumor of the Breast. Personal Contribution of 21 Cases. Il Giornale di chirurgia, 21, 453-456.

[9] Ranchere-Vince, D., Fontanière, B. and Labadie, M. (1998) Cytopathologie Mammaire. In: EMCGynécologie, Elsevier Masson, Paris. [816-F-10, 10 p].

[10] Toesca, A., Spitaleri, G., De Pas, T., Botteri, E., Gentilini, O., Bottiglieri, L., et al. (2012) Sarcoma of the Breast: Outcome and Reconstructive Options. Clinical Breast Cancer, 12, 438-444. https://doi.org/10.1016/j.clbc.2012.09.008

[11] Belkacemi, Y., Bousquet, G., Marsiglia, H., Ray-Coquard, I., Magné, N., Malard, Y., et al. (2008) Phyllodes Tumors of the Breast. International Journal of Radiation Oncology, Biology, Physics, 70, 492-500.

https://doi.org/10.1016/j.ijrobp.2007.06.059

[12] Confavreux, C., Lurkin, A., Mitton, N., Blondet, R., Saba, C., Ranchere, D., et al. (2006) Sarcomas and Malignant Phyllodes Tumours of the Breast: A Retrospective Study. European Journal of Cancer, 42, 2715-2721. https://doi.org/10.1016/j.ejca.2006.05.040

[13] Grenier, J., Delbaldo, C., Zelek, L. and Piedbois, P. (2010) Tumeurs phyllodes et sarcomes dusein: Mise au point. Bulletin du Cancer, 97, 1197-1207. https://doi.org/10.1684/bdc.2010.1174

[14] Morales-Vásquez, F., Gonzalez-Angulo, A.M., Broglio, K., Lopez-Basave, H.N., Gallardo, D., Hortobagyi, G.N., et al. (2007) Adjuvant Chemotherapy with Doxorubicin and Dacarbazine Has No Effect in Recurrence-Free Survival of Malignant Phyllodes Tumors of the Breast. The Breast Journal, 13, 551-556. https://doi.org/10.1111/j.1524-4741.2007.00510.x

[15] Zurrida, S., Bartoli, C., Galimberti, V., Squicciarini, P., Delledonne, V., Veronesi, P., et al. (1992) Which Therapy for Unexpected Phyllodes Tumour of the Breast? European Journal of Cancer, 28, 654-657. https://doi.org/10.1016/S0959-8049(05)80119-4

[16] Stebbing, J.F. and Nash, A.G. (1995) Diagnosis and Management of Phyllodes Tumour of the Breast: Experience of 33 Cases at a Specialist Centre. AAnnals of the Royal College of Surgeons of England, 77, 181-184.

[17] Zelek, L., Llombart-Cussac, A., Terrier, P., Pivot, X., Guinebretiere, J.M., Le Péchoux, C., et al. (2003) Prognostic Factors in Primary Breast Sarcomas: A Series of Patients with Long-Term Follow-up. Journal of Clinical Oncology, 21, 2583-2588. https://doi.org/10.1200/JCO.2003.06.080

[18] Adem, C., Reynolds, C., Ingle, J.N. and Nascimento, A.G. (2004) Primary Breast Sarcoma: Clinico-Pathologic Series from the Mayo Clinic and Review of the Literature. British Journal of Cancer, 91, 237-241. https://doi.org/10.1038/sj.bjc.6601920

[19] Fields, R.C., Aft, R.L., Gillanders, W.E., Eberlein, T.J. and Margenthaler, J.A. (2008) 
Treatment and Outcomes of Patients with Primary Breast Sarcoma. American Journal of Surgery, 196, 559-561. https://doi.org/10.1016/j.amjsurg.2008.06.010

[20] Berg, J.W., Decrosse, J.J., Fracchia, A.A. and Farrow, J. (1962) Stromal Sarcomas of the Breast: A Unified Approach to Connective Tissue Sarcomas Other than Cystosarcoma phyllodes. Cancer, 15, 418-424.

https://doi.org/10.1002/1097-0142(196203/04)15:2\%3C418::AID-CNCR2820150226 \%3E3.0.CO;2-V

[21] Bousquet, G., Confavreux, C., Magne, N., de Lara, C.T., Poortmans, P., Senkus, E., et al. (2007) Outcome and Prognostic Factors in Breast Sarcoma: A Multicenter Study from the Rare Cancer Network. Radiotherapy \& Oncology, 85, 355-361. https://doi.org/10.1016/j.radonc.2007.10.015

[22] Moore, M.P. and Kinne, D.W. (1996) Breast Sarcoma. Surgical Clinics of North America, 76, 383-392. https://doi.org/10.1016/S0039-6109(05)70445-X 